\title{
Recombinant elastomeric protein biopolymers: progress and prospects
}

\author{
Monica S Tjin, Pearlie Low and Eileen Fong \\ Genetically engineered protein biopolymers belong to a new family of polymers that have recently attracted interest due to their \\ highly modifiable material properties. It is now possible to use a bottom-up engineering process to design advanced, smart \\ materials for biomedical and engineering applications, such as energy storage and bioremediation. This review explores recent \\ developments in these genetically engineered protein biopolymers, with a particular emphasis on elastomeric biopolymers. Also \\ discussed are the future directions that this field will likely explore.
}

Polymer Journal (2014) 46, 444-451; doi:10.1038/pj.2014.65; published online 2 July 2014

\section{INTRODUCTION}

Genetically engineered protein biopolymers have recently attracted tremendous attention for various applications in engineering and materials science. With advances in recombinant technologies, it is now possible to have precise control over the genetic sequence and properties of a given protein biopolymer. As such, recombinant protein biopolymers can be specially designed to possess multifunctionalities, including self-assembling abilities, directed biological activities and even unique metal binding properties. These characteristics make recombinant proteins particularly useful for the preparation of a wide variety of functional materials for regenerative medicine and engineering applications.

In this focused review, we aim to provide an overview of the current prospects in elastomeric protein biopolymer research.

\section{ELASTIN}

Elastin is one of the most abundant extracellular matrix proteins found in organs where elasticity is of major importance, such as large arteries, elastic ligaments, lungs and skin. ${ }^{1-4}$ Elastin-like polypeptides (ELPs) consist of repetitive peptide sequences derived from the hydrophobic domain of mammalian tropoelastin, the precursor protein of elastin. The most commonly studied motif of ELPs is the pentapeptide motif (VPGXG) ${ }_{m}$, where $\mathrm{X}$ is known as a guest amino acid other than proline. The subscript $m$ describes the number of repeats, which typically ranges between 20 and 330 repeats. $^{5}$ Following pioneering studies on the development and characterization of ELPs by Urry and group, ${ }^{6,7}$ elastin-based biopolymers have been heavily investigated for a wide variety of applications.

A unique property of ELPs is their ability to undergo a sharp and reversible phase transition at a specific temperature known as the inverse transition temperature $\left(T_{\mathrm{t}}\right)$ or the lower critical solution temperature (LCST); both of these terms can be used interchangeably. ${ }^{8}$ ELPs undertake hydrophilic random coil conformations below their LCST and are highly soluble in water. Above their LCST, ELPs aggregate rapidly into micron-size particles that are visible to the naked eye. ${ }^{9}$ Such phase transitions are reversible and can be rapidly triggered by temperature shifts. Urry and group ${ }^{6,7}$ demonstrated that this LCST is highly dependent on the amino acid composition of the peptide repeat. Therefore, the LCST can be tailored to suit the application by changing the guest residue $\mathrm{X}$ in the pentapeptide motif (VPGXG) ${ }_{m} \cdot{ }^{5}$ Moreover, this inverse transition temperature enables ELPs to be easily purified simply by repeated centrifugation while cycling the temperature above and below its LCST; this technique is termed ITC or inverse thermal cycling. ${ }^{10}$

Upon changes in temperature, $\mathrm{pH}$ and salt concentration, ELPs self-assemble into organized network structures ${ }^{11}$ (Figure 1). Such self-assembling behavior is particularly useful for tissue engineering and drug delivery applications. ELPs can also serve as templates for nanomaterial synthesis. ${ }^{12-14}$

\section{ELPs in tissue engineering}

Tissue engineering has evolved into a multidisciplinary field involving materials science, engineering and biology. To serve as functional substitutes for damaged tissues, biomaterials are now expected to mimic the biological, mechanical and topographical characteristics of the native tissues they are replacing.

ELP biopolymers are attractive candidates for tissue engineering for several reasons. First, ELPs are known to have excellent biocompatibility and are degradable into natural amino acids that cause a minimum amount of cytotoxicity, immune response and inflammation. ${ }^{10,15-17}$ One of the earliest examples of ELP use in tissue engineering was work performed by Setton and Chilkoti. ${ }^{18}$ In this case, ELPs were used to create an injectable three-dimensional matrix to entrap chondrocytes for cartilaginous tissue repair. ${ }^{18}$ In vitro studies revealed that the encapsulated chondrocytes retained a 
Molecular Structure of Poly (VPGVG)

a

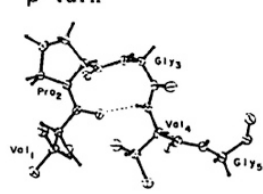

b

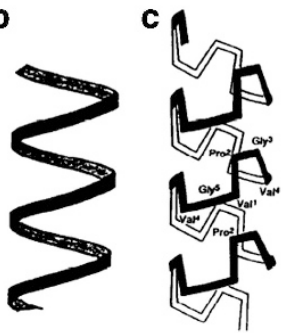

d $\beta$-spiral
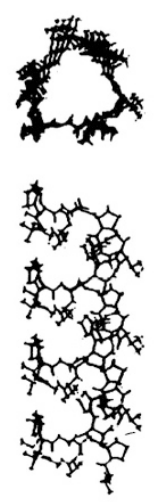
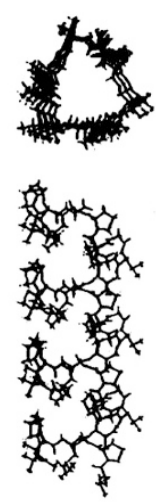

e twisted filament of $\beta$-spirals

Figure 1 The self-assembling structure of elastin-like polypeptide (ELP) upon raised temperature from a $\beta$-turn helical structure to a twisted filament of several $\beta$-spirals. Reproduced with permission from Urry. ${ }^{11}$

a

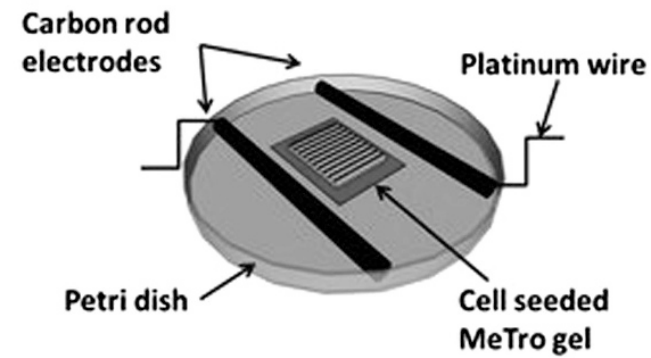

b

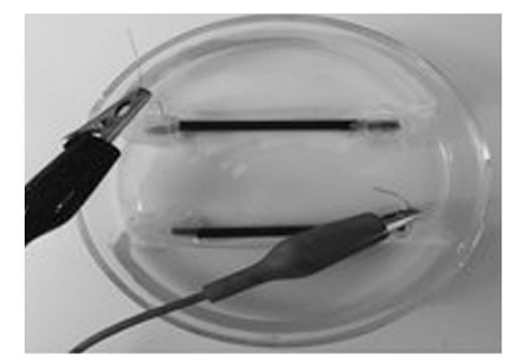

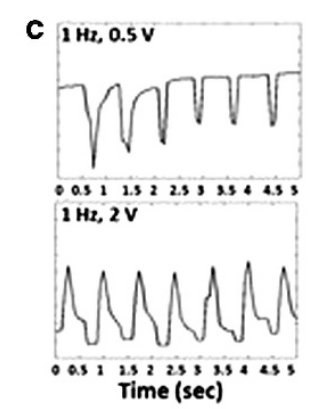

Time (sec)

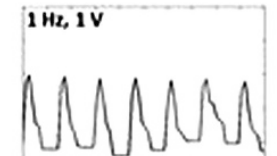

oas: is 2 253 is ass

$1 \mathrm{~Hz}, 3 \mathrm{~V}$

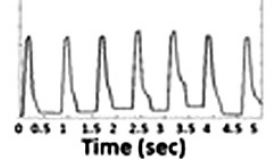

Time (sec)

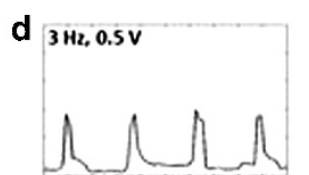

oas is is 23, 25.45s

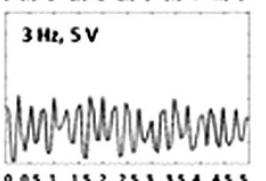

0.512 .322532 .5445 Time (sec)

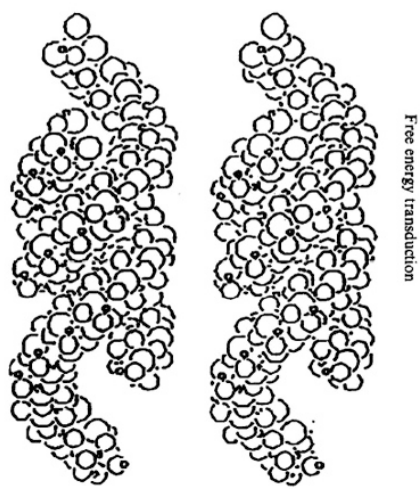

.
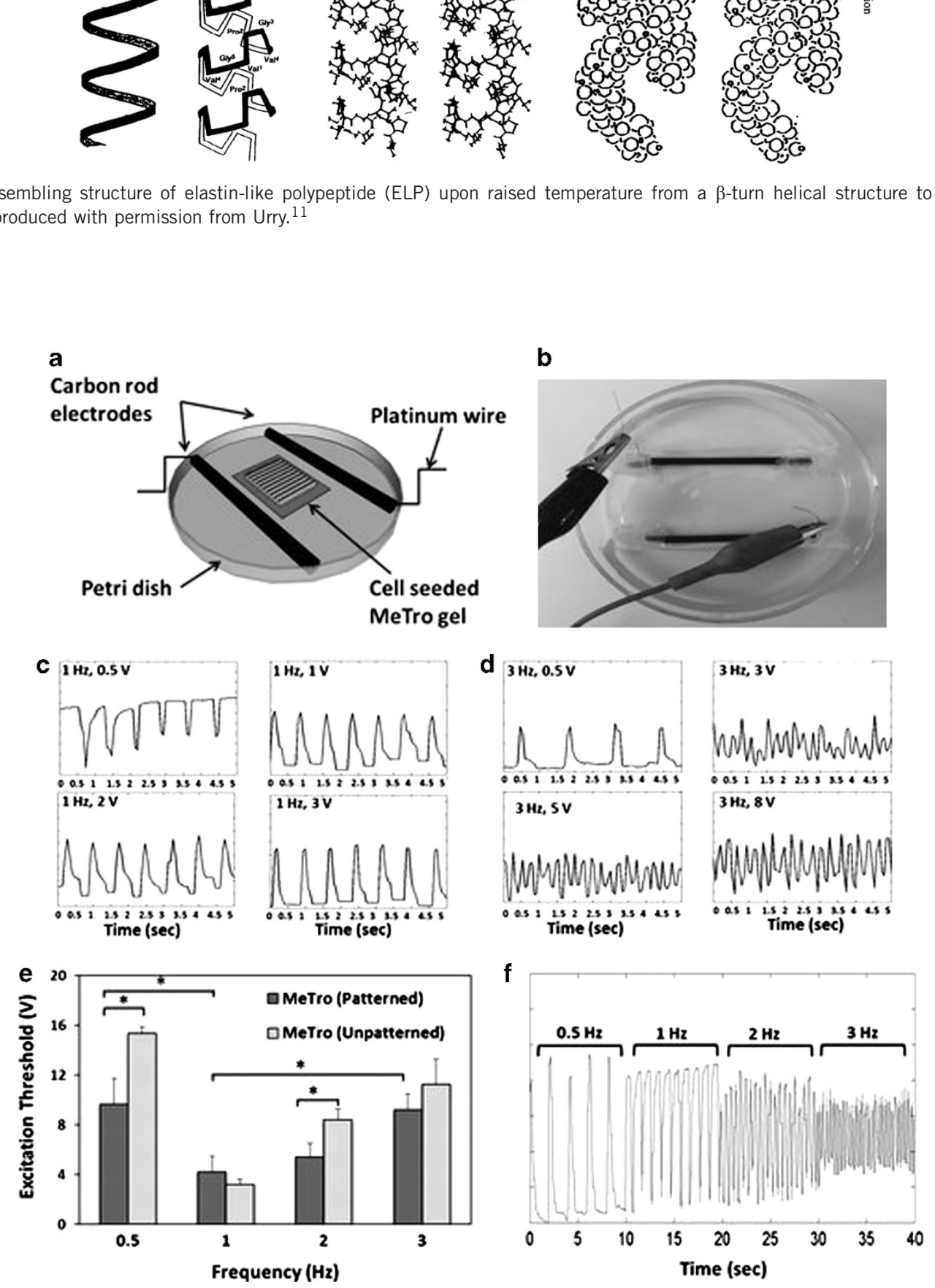

Figure 2 Induction of synchronized beating in cardiomyocytes on micropatterned methacrylated tropoelastin (MeTro) gels by using electrical stimulation. (a, b). Electrical stimulation chamber setup of cardiomyocytes cultured on MeTro gels. (c-f). Contractile responses to electrical stimulation at various voltages and frequencies to induce synchronized beating. Reproduced with permission from Annabi et al. ${ }^{28} \mathrm{~A}$ full color version of this figure is available at Polymer Journal online. 
rounded morphology and a chondrocytic phenotype. The authors demonstrated that when human adipose-derived stem cells were encapsulated, ELP gels induce chondrocytic differentiation, even in the absence of chondrocyte-specific growth factors. ${ }^{18}$ A similar study was also performed by Haider et al., ${ }^{19}$ where human mesenchymal stem cells were used for chondrogenesis. These reports suggest that ELP-based biopolymers have great potential for use in cartilage tissue repair. However, uncrosslinked ELPs exhibit shear modulus several orders lower than cartilage. Therefore, their mechanical integrity is insufficient to match and support functional cartilage repair.

ELPs have also been chemically crosslinked to produce scaffolds with improved mechanical integrity using well-established crosslinking methods. Common examples include the following: tissue transglutaminase, which catalyzes covalent bond formation between glutamine residues and primary amines; the amine reactive crosslinker $\beta$-[tris(hydroxymethyl) phosphino] propionic acid; and an NHS-ester crosslinker that crosslinks primary amines (of lysine and arginine residues). ${ }^{20-22}$ The use of tissue transglutaminase to crosslink ELP is favorable; gelation occurs under physiological conditions, and the reaction can be performed in situ with little effect on living encapsulated cells. However, this crosslinking reaction proceeded over a long period of time, limiting its clinical use. Similarly, Nagapudi et al. ${ }^{23}$ also reported the use of photoactive methacrylate polymers for the crosslinking of ELPs under UV and visible light for cell encapsulation.

In addition to cell encapsulation, other uses of ELPs in tissue engineering include tissue-engineered vascular grafts. Tirrell and group $^{24}$ designed a small diameter vascular graft using ELPs fused with fibronectin CS5 domains. The CS5 domain present within the fusion construct enhanced endothelial cell adhesion. ${ }^{25,26}$ Crosslinked films made from the CS5-containing ELPs also exhibited mechanical properties similar to that of native elastin (elastic moduli ranges between 0.3 and $0.6 \mathrm{MPa}) .{ }^{17}$ ELP-based biopolymers can be designed to have increased and more integrin-specific bioactivities through the incorporation of selective cell-binding domains. For example, ELPs containing the full-length fibronectin domains 9 and 10 were shown to engage alpha5betal integrins with increased affinities, leading to faster wound closure. ${ }^{27}$

Recently, Annabi et al. ${ }^{28}$ reported the use of an elastin-based biopolymer in cardiac tissue engineering. Specifically, a methacrylated tropoelastin hydrogel was developed that had high resilience (approximately 400\%) upon stretching and deformed reversibly with minimum energy loss. ${ }^{29}$ In this work, the micropatterned methacrylated tropoelastin hydrogel was also shown to direct the alignment of cardiomyocytes and synchronize their contractile properties in vitro ${ }^{28}$ (Figure 2), mimicking those of native myocardium.

Although elastin is found abundantly in skin, only several reports on the application of elastin-based biomaterials as skin substitutes have been completed. One such work by Rnjak-Kovacina et al. ${ }^{30}$ used electrospun recombinant human tropoelastin mixed with bovine collagen to create composite porous scaffolds for use as dermal substitutes. Their in vivo cell culture results demonstrated that the blending of both proteins supported cell infiltration, cell proliferation and new capillary formation when compared with Integra, a commercially available dermal substitute. Nonetheless, most of the literature is focused on designing the optimal scaffold topography or architecture for dermal fibroblasts. Our group has designed and produced ELP fusion biopolymers specifically for artificial skin substrates. In our work, each ELP fusion protein sequence was designed to contain cell-binding domains derived from native fibronectin, laminin and collagen. Such fusion constructs were designed to target major integrin-extracellular matrix interactions utilized by human skin keratinocytes. We found that keratinocyte interactions with the various cell-binding domains present in each ELP resulted in differing rates of keratinocytes adhesion and motility. ${ }^{31}$ Hence, it is possible to design cell-instructive biomaterials that also mimic the microenvironment of human tissues.

\section{ELPs for the synthesis of inorganic materials}

The concept of using of ELP fusion proteins for metal binding was first demonstrated by Chen and coworkers. ${ }^{32-35}$ Specifically, ELP fusion proteins capable of recognizing and binding heavy metals were developed for the purpose of bioremediation. In their reports, ELP fusion proteins were able to bind heavy metals in water and were subsequently recovered by utilizing the temperature-responsive characteristics of ELPs. ${ }^{32}$ Chen and workers ${ }^{33,34}$ also demonstrated the efficiency of ELPs containing two metal-binding domains, polyhistidine and phytochelatin, in cadmium removal. When phytochelatin was used as the metal-binding domain for ex situ soil washing, a fivefold increase in cadmium removal was observed compared to polyhistidine. Phytochelatin exhibited higher binding affinity and binding capacity compared to cadmium. In another study, $90 \%$ of cadmium was removed in less than an hour using a low concentration of $0.25 \mathrm{~mm}$ ELP biopolymer; this was compared to 4 mm EDTA. ${ }^{33,34}$ Subsequent studies on other metal-binding domains have also been reported, including a study on the bacterial metalloregulatory protein MerR, which has a very high affinity to mercury. In this work, it was reported that the retrieval of mercury in Lake Elsinore, CA, USA, water was highly selective even in the presence of unrelated heavy metals at an excess of 100 -fold. ${ }^{35}$

ELPs were also explored as templates for the synthesis of inorganic metallic nanoparticles. ${ }^{36,37}$ For example, ELPs containing silverbinding domains were designed and used for the biomimetic synthesis of silver nanoparticles. Specifically, the fusion protein GPG-AG3 discovered by Naik and group, ${ }^{39}$ which contains a tropoelastin-like domain (that is, $\mathrm{GPG}^{38}$ ) and the AG3 sequence (AYSSGAPPMPPF), possessed the ability to reduce choloaurate $\left(\left[\mathrm{AuCl}_{4}\right]^{3-}\right)$ to nucleate gold nanoparticles or $\mathrm{Ag}^{+}$to $\mathrm{Ag}^{0}$ under physiological conditions. ${ }^{40}$ In a report by Anh et al., ${ }^{40}$ GPG-AG3 fusion proteins presented in the form of protein aggregates or

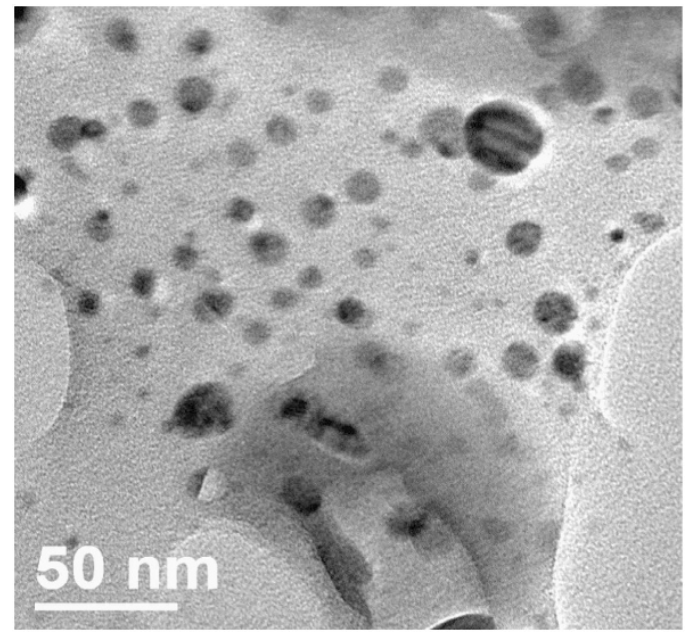

Figure 3 High resolution transmission electron microscopy image of silver nanoparticles nucleated on GPG-AG3 after 3 days. Reproduced with permission from Anh et al. ${ }^{40}$ 
crosslinked spun-coated thin films were able to nucleate silver nanoparticles from soluble silver precursors (Figure 3). Both forms of GPG-AG3 materials containing nucleated silver nanoparticles possess antibacterial properties, ${ }^{40}$ demonstrating promising use as antibacterial wound dressings and biomedical implant coatings.

Apart from their biomedical applications, ELPs also hold promise for use in the biomineralization of inorganic nanomaterials. Biomineralization is a natural phenomenon that occurs in living organisms. It involves a combination of concerted mechanisms including bioaccumulation, reduction and mineralization processes to form hard tissues or to protect them from metal toxicity. ${ }^{41,42}$ There has been increasing advancement in the creation of multifunctional hierarchical inorganic composites using biological systems as templates, which have been inspired by native biomineralization processes. For example, wire-shaped flagella from bacteria and rodlike viruses (for example, the tobacco mosaic virus and M13) have been used or modified with metal-binding motifs to biomimetically fabricate various metal nanowire/tube structures. ${ }^{43}$ In our laboratory, we have explored the use of ELPs as a versatile template for the fabrication of long-range noble metal nanostructures. For example, Guo et al $^{44}$ have successfully utilized the self-assembling GPG-AG3 fusion protein for the biomineralization of noble metal nanoparticles. In this work, the porous nanofibers Pt and Pd were obtained and had excellent catalytic capabilities (manuscript under review).

While ELPs and ELP fusion proteins are a promising class of biomaterials for tissue engineering and regenerative medicine, the use of ELPs for other important engineering applications such as bioremediation, energy storage and catalysis is also being explored.

\section{SILK}

Silk is another class of materials with unique mechanical properties. Silk and silk-like biopolymers have high strength-to-weight ratios and mechanical properties that span a wide range of moduli (3-10 GPa). ${ }^{45}$ Silk proteins contain highly repetitive protein sequences that can be crystalline or non-crystalline in nature. For example, the crystalline region from silkworm Bombyx mori fibroin is mostly composed of glycine, alanine and serine in a $3: 2: 1$ ratio (that is, GAGAGSGAAG[SGAGAG] $\left.{ }_{8} \mathrm{Y}\right){ }^{46}$ Likewise, the repetitive motifs of spider silk spindroin from orb-weaving Nephila clavipes dragline silk (YGGLGSQGAGRGG) have also been identified. ${ }^{47,48}$

The versatile mechanical properties of silk make silk-like biopolymers very attractive for use in biomedical applications. B. mori silk fibers, for example, have been used as sutures since the end of 19th century. Dragline spider silk has also been heavily studied for its high strength-to-weight ratio. However, the translation of silk-based biomaterials to clinical use has been limited by difficulties in harvesting native silk proteins. It is particularly difficult to obtain scalable amounts of dragline silk because the large-scale farming of spiders is not possible. For this reason, recombinant silk proteins and silk-like biopolymers have gained popularity; large amounts of materials can be biosynthetically produced in various host systems, including bacteria, ${ }^{49}$ insect cells, ${ }^{50,51}$ mammalian cells ${ }^{52}$ and yeast. ${ }^{53}$ Many synthetic genes encoding $B$. mori silk-like sequences, such as the six amino acid repeat GAGAGS, $\left[(\mathrm{AG})_{3} \mathrm{PEG}\right]$ and $\left[(\mathrm{AG})_{3} \mathrm{EG}\right]$, have been cloned and expressed in bacterial hosts such as Escherichia coli. $^{49,54,55}$ Engineered spindroins have also been developed and recombinantly produced in E. coli; these include the ADF3 and ADF4 sequences from Araneus diadematus. ${ }^{56,57}$ Recombinant spindroins have also been produced in large quantities, with protein yields up to $360 \mathrm{mgl}^{-1}$, using bacterial fermentation methods. ${ }^{58}$ Therefore, the use of such proteins on an industrial scale is promising.
Like ELPs, the increasing popularity of silk has stimulated a widespread interest in silk-based fusion proteins. For example, fusion proteins containing silk and extracellular matrix motifs derived from collagen, laminin and fibronectin have been developed. Such proteins have been shown to increase the attachment and spreading of various cells compared to those cultured on unmodified silk nanofibers. ${ }^{59-63}$ In terms of materials processing, it has also been shown that recombinant spindroins have the capability to be processed into a wide range of morphologies (Figure 4). ${ }^{64,65}$ To date, silk-based biopolymers have been investigated for use as biomaterial scaffolds for the following: skin $^{66,67}$; skeletal tissue such as cartilage, ${ }^{62,68-70}$ bone $e^{71,72}$ and ligaments/tendons ${ }^{73}$; vascular tissues ${ }^{74}$; and nerve grafts. ${ }^{75}$ With continuing advancement in recombinant technologies, silk-based biopolymers will likely continue to be an interesting and important class of materials in tissue engineering.

\section{RESILIN}

Resilin is another structural protein that is recently of interest in tissue engineering research, largely due to its unique mechanical properties. Resilin is an elastomeric protein found commonly in the ligament and tendons of insects. ${ }^{76}$ In a previous study, resilin isolated from locust tendons was able to store large amounts of energy with little loss to heat. ${ }^{77}$ Native resilin is composed of random coils, crosslinked by diand tri-tyrosine links. This crosslinking results in a stable and flexible three-dimensional network, conferring to resilin its elastomeric properties. $^{78}$ The elasticity of resilin is largely attributed to the high content of glycine and proline residues, which form $\beta$-turn and polyproline II conformations. ${ }^{79,80}$ Like most structural proteins previously discussed, a recombinant resilin-like biopolymer could also be reproduced using E. coli expression hosts. The CG15920 gene from Drosophila melanogaster is one of the most popular domains found in recombinant resilin-like biopolymers. ${ }^{81}$ Particularly, the repetitive motif GGRPSDSYGAPGGGN located in the N-terminal region of CG15920 has been widely studied. For instance, Kaplan and group $^{82}$ examined the protein exons 1 and 3; exon 1 exhibited $90 \%$ resilience compared to $63 \%$, which made exon 1 the chosen domain to mimic native resilin. The authors also sought an alternative di-tyrosine formation technique for resilin-based hydrogels using a citrate-modified photo-Fenton system. The study revealed interesting adhesive properties for the crosslinked hydrogels, as L-3,4dihydroxyphenylalanie was also formed. This crosslinked resilinbased hydrogel displayed a high resilience of $90 \%$ by withstanding over 50 cycles of extension using an atomic force microscope $e^{82}$ (Figure 5).

Li and Kiick ${ }^{80}$ demonstrated that recombinant resilin-like hydrogels have comparable mechanical strength and extensibility to native forms. The authors added RGD cell-binding domains to the resilinlike polypeptides (RLPs), and crosslinked the fusion proteins using Tris(hydroxymethyl phosphine). The authors were able to obtain mechanically stable hydrogels, which could maintain the viability of primary human mesenchymal stem cells and mouse fibroblast NIH-3T3 cells. ${ }^{83,84}$ Separately, composite hydrogels consisting of resilin-like polypeptides and polyethylene glycol were developed by designing cysteine residues in resilin-like polypeptides as crosslinking sites for the vinyl sulfone groups in polyethylene glycol; these hydrogels were able to support the viability and spreading of encapsulated human aortic adventitial fibroblasts. ${ }^{85}$ Likewise, hybrid biopolymers containing resilin-like, elastin-like and collagen-like domains were also reported to have bioactivity. ${ }^{86}$

Recently, Li and group ${ }^{87-89}$ reported on an artificial protein containing periodic repeats of GB1 and resilin (Figure 6). The GB1 

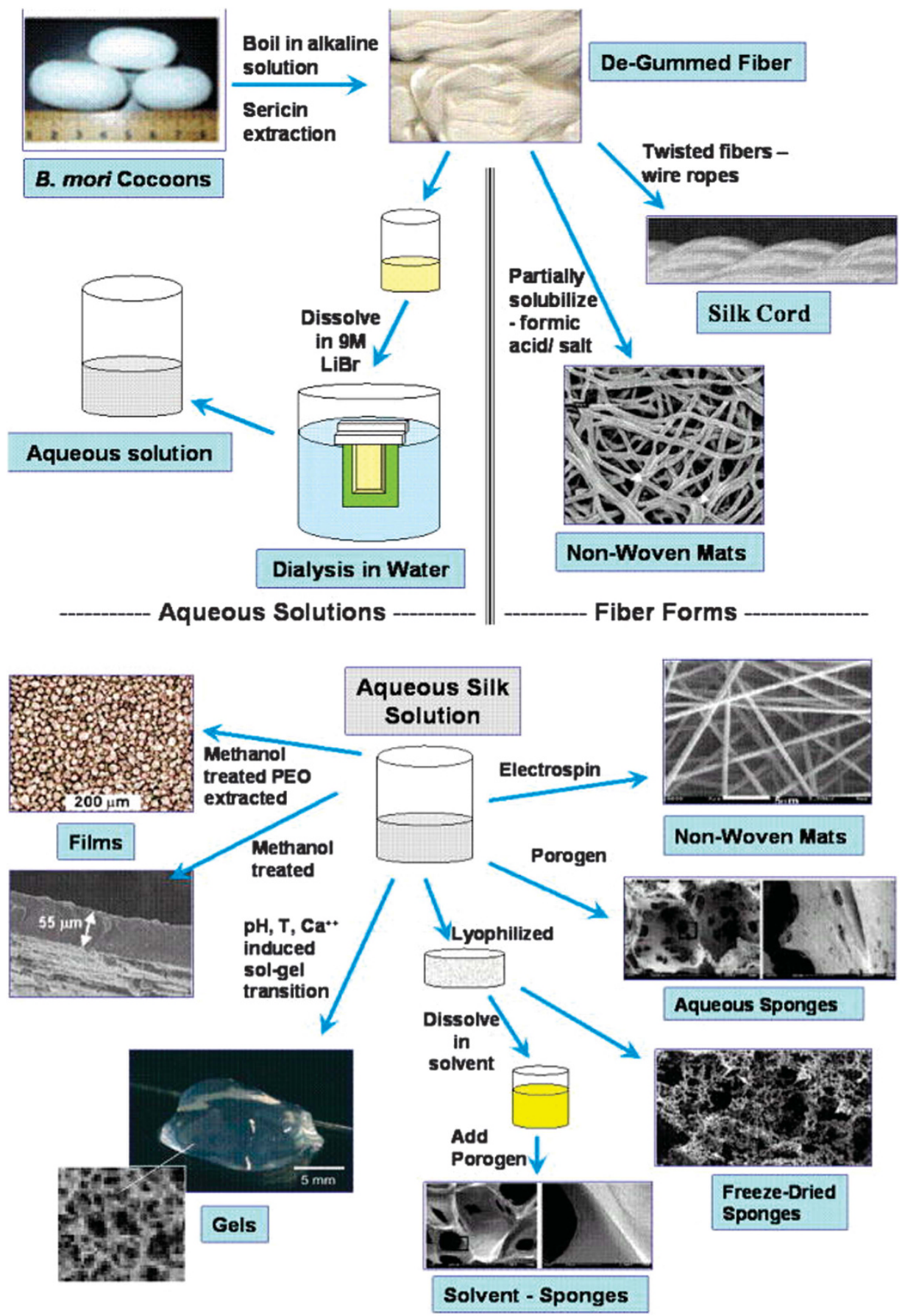

Figure 4 Processing of silk fibroin into various morphologies. Reproduced with permission from Vepari and Kaplan. ${ }^{65}$

polyprotein is derived from the streptococcal B1 immunoglobulinbinding domain of protein G. This polypeptide has been shown to possess mechanical stability over long periods of continuous stretching-relaxation cycles. ${ }^{87}$ In their work, crosslinked GB1-resilin scaffolds had an elastic modulus of approximately $50 \mathrm{kPa}$ (at $15 \%$ strain) and could be stretched up to $135 \% .{ }^{89}$ In a follow-up study, these authors demonstrated that the elastic stiffness of crosslinked GB1-resilin scaffolds could also be fine-tuned by controlling the crosslinking density. This yielded scaffolds with moduli ranging between 10 and $65 \mathrm{kPa} .{ }^{90}$

\section{TITIN}

Titin is a major component of human muscle sarcomeres; it is also the largest single polypeptide (approximately $4 \mathrm{MDa}$ ) known in nature. ${ }^{91-96}$ Native titin consists of long linear chains of approximately 300 modular domains, of which $90 \%$ are structured. Of these structured domains, the most widely studied are the fibronectin-like type III and the immunoglobulin-like domains. In contrast, the unstructured domains are flexible and rich in proline $(\mathrm{P})$, glutamate $(\mathrm{E})$, valine $(\mathrm{V})$ and lysine $(\mathrm{K})$ (and referred to as PEVK). ${ }^{92}$ 

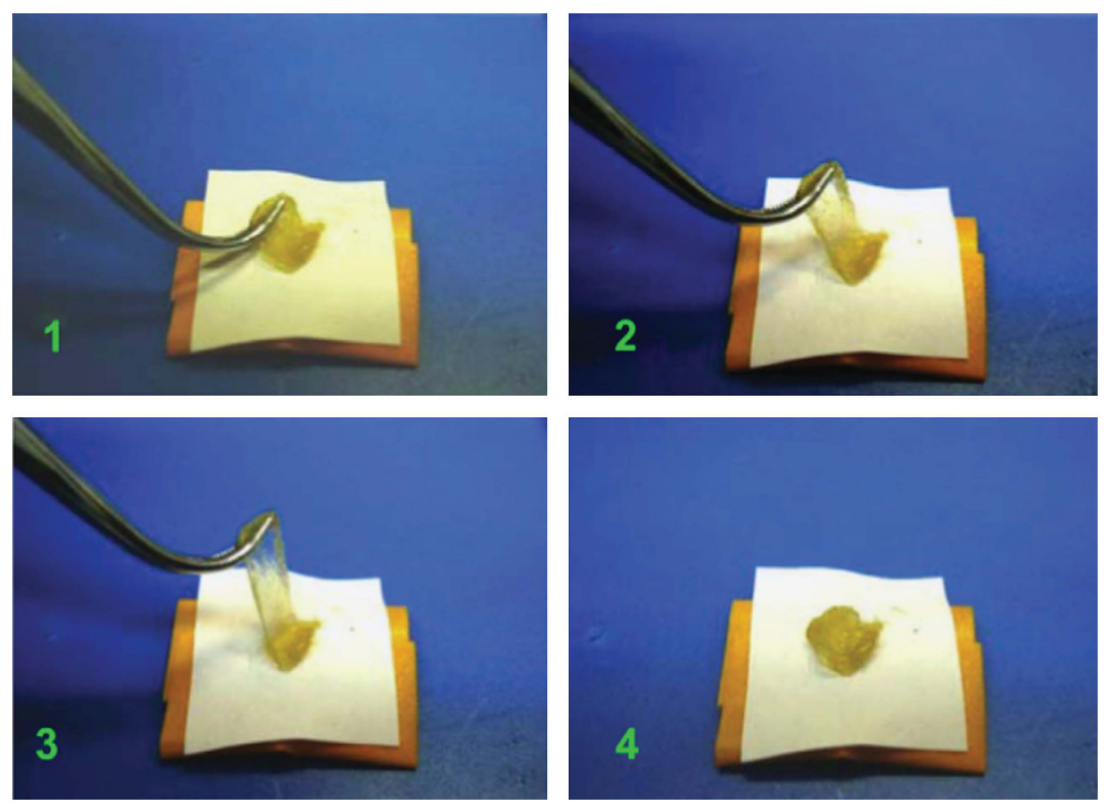

Figure 5 Photo-fenton crosslinked exon 1 resilins displaying high resilience; resilins withstood over 50 cycles of mechanical extension without any plastic deformation. Reproduced with permission from Qin et al. ${ }^{82}$

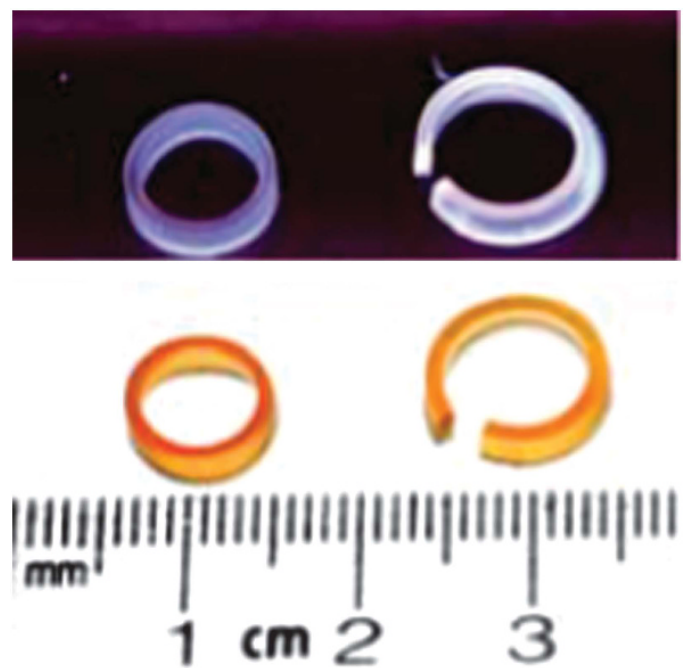

Figure 6 GB1-resilin hydrogels with di-tyrosine crosslinks shown as white and orange under ultraviolet and visible illumination, respectively. Reproduced with permission from Lv et al. ${ }^{89}$

Native titin has been widely studied to better understand the mechanisms responsible for the extensibility and the elastic behavior of human muscle. Single-molecule force studies have shown that the high mechanical strength, fracture toughness and the elasticity of titin are due to the sequential folding/unfolding of its structured domains at the molecular level. ${ }^{97-102}$ It has been suggested that the unfolding of certain immunoglobulin-like and PEVK domains is responsible for the passive elasticity observed in muscle..$^{92,94,103,104}$ Specifically, the immunoglobulin-like 27 domain in titin is composed of 89 amino acids and adopts a $\beta$-sandwich fold structure ${ }^{105}$; this domain can be unfolded with a characteristic force of $204 \mathrm{pN} .{ }^{97}$ It was further proposed that the mechanical force to resist unfolding in immunoglobulin-like 27 is provided by hydrogen bonds between two parallel terminal $\beta$-strands in a sandwich formation. ${ }^{105}$

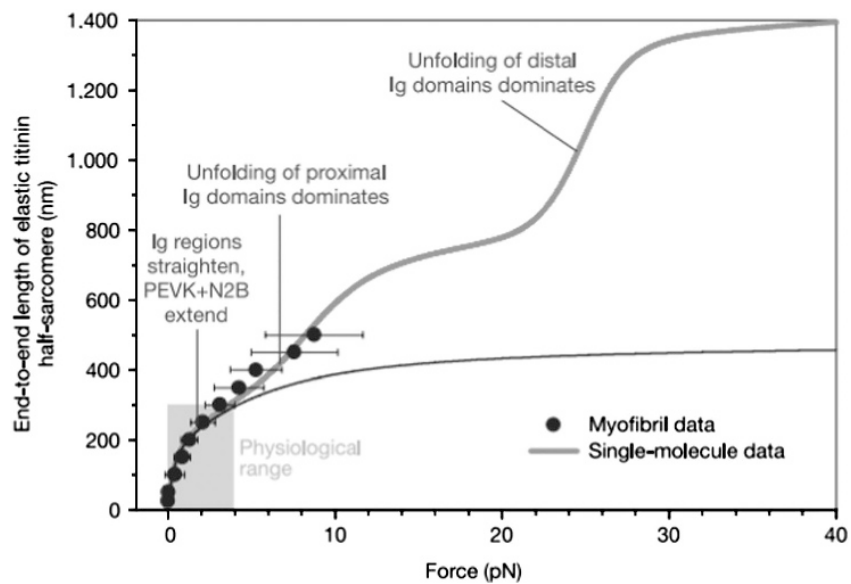

Figure 7 Single-molecule force microscopy data of cardiac titin in agreement with cardiac myofibril data in the physiological range of sarcomere extension. Reproduced with permission from Li et al. ${ }^{97} \mathrm{~A}$ full color version of this figure is available at Polymer Journal online.

Conversely, the randomly folded PEVK domain contains $75 \%$ proline, glutamate, valine and lysine residues. It has been proposed that the unfolding of PEVK domains accounts for the flexible and extensible behavior of human muscle. ${ }^{94,106,107}$

Given the unique extensibility of titin, titin-based biopolymers have also been investigated. Li et al. ${ }^{97}$ have produced a series of recombinant proteins containing various immunoglobulin-like and PEVK domains and studied their mechanical properties using singlemolecule force microscopy. In this work, the authors found that the immunoglobulin-like 27 domain unfolded at a force of $204 \mathrm{pN}$. Conversely, the extension of PEVK and N2B (unique sequences of tandem immunoglobulin-like and PEVK segments) regions in cardiac I-band titin was observed to be an average of 68 and $209 \mathrm{~nm}$, respectively. The collective extension contributed by these random domains measured by single-molecule force microscopy is $300 \mathrm{~nm}$, 
consistent with cardiac myofibril data ${ }^{97}$ (Figure 7). These findings suggest that it may be possible to recreate recombinant biopolymers that have muscle-like mechanical properties.

At present, research on titin-based biopolymers is largely focused on understanding their mechanical behavior at the single-molecule level. However, it is likely that scaffolds derived from titin-based biopolymers have tremendous potential in tissue-engineering applications, given their unique muscle-like properties.

\section{SUMMARY}

The ability to tailor both the chemical and physical properties of recombinant biopolymers has created a wide range of opportunities in the end applications of these materials. This review aims to provide the scientific community with an overview of current trends in the field of recombinantly engineered elastomeric protein biopolymers. In this article, we summarized current research on some biopolymers, and we described ongoing work on unpublished recombinant biopolymers developed in our laboratory. We also evaluated their potential applications in biomedicine and other engineering disciplines, such as inorganic nanomaterial synthesis and bioremediation.

\section{ACKNOWLEDGEMENTS}

We acknowledge funding from the Ministry of Education AcRF Tier 1 (RG41) Tjin and Low are supported by the Research Student Scholarship (RSS) from Nanyang Technological University, Singapore.

1 Wise, S. G., Mithieux, S. M., Raftery, M. J. \& Weiss, A. S. Specificity in the coacervation of tropoelastin: solvent exposed lysines. J. Struct. Biol. 149, 273-28 (2005).

2 Vrhovski, B., Jensen, S. \& Weiss, A. S. Coacervation characteristics of recombinant human tropoelastin. Eur. J. Biochem. 250, 92-98 (1997)

3 Vrhovski, B. \& Weiss, A. S. Biochemistry of tropoelastin. Eur. J. Biochem. 258, 1-18 (1998).

4 Bellingham, C. M., Lillie, M. A., Gosline, J. M., Wright, G. M., Starcher, B. C., Bailey, A. J., Woodhouse, K. A. \& Keeley, F. W. Recombinant human elastin polypeptides self-assemble into biomaterials with elastin-like properties. Biopolymers 70, 445-455 (2003).

5 Meyer, D. E. \& Chilkoti, A. Quantification of the effects of chain length and concentration on the thermal behavior of elastin-like polypeptides. Biomacromole cules 5, 846-851 (2004).

6 Urry, D. W. \& Long, M. M. Conformations of the repeat peptides of elastin in solution: an application of proton and carbon-13 magnetic resonance to the determination of polypeptide secondary structure. Crit. Rev. Biochem. 4, 1-45 (1976).

7 McPherson, D. T., Morrow, C., Minehan, D. S., Wu, J., Hunter, E. \& Urry, D. W. Production and purification of a recombinant elastomeric polypeptide, G-(VPGVG)19 VPGV, from Escherichia coli. Biotechnol. Prog. 8, 347-352 (1992).

8 Urry, D. W. Physical chemistry of biological free energy transduction as demonstrated by elastic protein-based polymers. J. Phys. Chem. B 101, 11007-11028 (1997).

9 Meyer, D. E. \& Chilkoti, A. Genetically encoded synthesis of protein-based polymers with precisely specified molecular weight and sequence by recursive directional ligation: examples from the elastin-like polypeptide system. Biomacromolecules $\mathbf{3}$, 357-367 (2002).

10 Meyer, D. E., Trabbic, C. K. \& Chilkoti, A. Protein purification by fusion with an environmentally responsive elastin-like polypeptide: effect of polypeptide length on the purification of thioredoxin. Biotechnol. Prog. 17, 720-728 (2001).

11 Urry, D. W. Free energy transduction in polypeptides and proteins based on inverse temperature transitions. Prog. Biophys. Mol. Biol. 57, 23-57 (1992).

12 Wright, E. R., McMillan, R. A., Cooper, A., Apkarian, R. P. \& Conticello, V. P. Thermoplastic elastomer hydrogels via self-assembly of an elastin-mimetic triblock polypeptide. Adv. Funct. Mater. 12, 149-154 (2002)

13 MacKay, J. A., Chen, M., McDaniel, J. R., Liu, W., Simnick, A. J. \& Chilkoti, A. Selfassembling chimeric polypeptide-doxorubicin conjugate nanoparticles that abolish tumours after a single injection. Nat. Mater. 8, 993-999 (2009).

14 Zhang, S. Fabrication of novel biomaterials through molecular self-assembly. Nat Biotechnol. 21, 1171-1178 (2003).

15 Megeed, Z., Haider, M., Li, D., O’Malley, B. W. Jr, Cappello, J. \& Ghandehari, H. In vitro and in vivo evaluation of recombinant silk-elastinlike hydrogels for cancer gene therapy. J. Control. Rel. 94, 433-445 (2004).

16 Urry, D. W. Elastic molecular machines in metabolism and soft-tissue restoration. Trends Biotechnol. 17, 249-257 (1999).

17 Nicol, A., Gowda, D. C., Parker, T. M. \& Urry, D. W. Elastomeric polytetrapeptide matrices: hydrophobicity dependence of cell attachment from adhesive (GGIP)n to nonadhesive (GGAP)n even in serum. J. Biomed. Mater. Res. 27, 801-810 (1993).
18 Betre, H., Ong, S. R., Guilak, F., Chilkoti, A., Fermor, B. \& Setton, L. A. Chondrocytic differentiation of human adipose-derived adult stem cells in elastin-like polypeptide. Biomaterials 27, 91-99 (2006).

19 Haider, M., Cappello, J., Ghandehari, H. \& Leong, K. W. In vitro chondrogenesis of mesenchymal stem cells in recombinant silk-elastinlike hydrogels. Pharm. Res. 25, 692-699 (2008).

20 McHale, M. K., Setton, L. A. \& Chilkoti, A. Synthesis and in vitro evaluation of enzymatically cross-linked elastin-like polypeptide gels for cartilaginous tissue repair. Tissue Eng. 11, 1768-1779 (2005).

21 Nettles, D. L., Haider, M. A., Chilkoti, A. \& Setton, L. A. Neural network analysis identifies scaffold properties necessary for in vitro chondrogenesis in elastin-like polypeptide biopolymer scaffolds. Tissue Eng. Part A 16, 11-20 (2010).

22 Lim, D. W., Nettles, D. L., Setton, L. A. \& Chilkoti, A. In situ cross-linking of elastinlike polypeptide block copolymers for tissue repair. Biomacromolecules 9, 222-230 (2008).

23 Nagapudi, K., Brinkman, W. T., Leisen, J. E., Huang, L., McMillan, R. A., Apkarian, R. P., Conticello, V. P. \& Chaikof, E. L. Photomediated solid-state cross-linking of an elastin mimetic recombinant protein polymer. Macromolecules 35, 1730-1737 (2002).

24 Heilshorn, S. C., DiZio, K. A., Welsh, E. R. \& Tirrell, D. A. Endothelial cell adhesion to the fibronectin CS5 domain in artificial extracellular matrix proteins. Biomaterials 24 4245-4252 (2003)

25 Liu, J. C., Heilshorn, S. C. \& Tirrell, D. A. Comparative cell response to artificial extracellular matrix proteins containing the RGD and CS5 cell-binding domains. Biomacromolecules 5, 497-504 (2004).

26 Welsh, E. R. \& Tirrell, D. A. Engineering the extracellular matrix: a novel approach to polymeric biomaterials. I. Control of the physical properties of artificial protein matrices designed to support adhesion of vascular endothelial cells. Biomacromolecules 1, 23-30 (2000).

27 Fong, E. \& Tirrell, D. A. Collective cell migration on artificial extracellular matrix proteins containing full-length fibronectin domains. Adv. Mater. 22, 5271-5275 (2010).

28 Annabi, N., Tsang, K., Mithieux, S. M., Nikkhah, M., Ameri, A., Khademhosseini, A. \& Weiss, A. S. Highly elastic micropatterned hydrogel for engineering functional cardiac tissue. Adv. Funct. Mater. 23, 4950-4959 (2013).

29 Annabi, N., Mithieux, S. M., Zorlutuna, P., Camci-Unal, G., Weiss, A. S. \& Khademhosseini, A. Engineered cell-laden human protein-based elastomer Biomaterials 34, 5496-5505 (2013).

30 Rnjak-Kovacina, J., Wise, S. G., Li, Z Maitz, P. K. M., Young, C. J., Wang, Y. \& Weiss, A. S. Electrospun synthetic human elastin:collagen composite scaffolds for dermal tissue engineering. Acta Biomaterialia 8, 3714-3722 (2012).

31 Tjin, M. S., Chua, A. W. C., Ma, D. R., Lee, S. T. \& Fong, E. Human epiderma keratinocyte cell response on integrin-specific artificial extracellular matrix proteins. Macromol. Biosci. (e-pub ahead of print 2 May 2014; doi:10.1002/mabi.201400015).

32 Kostal, J., Prabhukumar, G., Lao, U. L., Chen, A., Matsumoto, M., Mulchandani, A. \& Chen, W. Customizable biopolymers for heavy metal remediation. J. Nanopart. Res. 7 , 517-523 (2005).

33 Lao, U. L., Chen, A., Matsumoto, M. R., Mulchandani, A. \& Chen, W. Cadmium removal from contaminated soil by thermally responsive elastin (ELPEC20) biopolymers. Biotechnol. Bioeng. 98, 349-355 (2007).

34 Prabhukumar, G., Matsumoto, M., Mulchandani, A. \& Chen, W. Cadmium remova from contaminated soil by tunable biopolymers. Environ. Sci. Technol. 38, 3148-3152 (2004).

35 Kostal, J., Mulchandani, A., Gropp, K. E. \& Chen, W. A temperature responsive biopolymer for mercury remediation. Environ. Sci. Technol. 37, 4457-4462 (2003).

36 Naik, R. R., Stringer, S. J., Agarwal, G., Jones, S. E. \& Stone, M. O. Biomimetic synthesis and patterning of silver nanoparticles. Nat. Mater. 1, 169-172 (2002).

37 Kim, J., Sadowsky, M. J. \& Hur, H. G. Simultaneous synthesis of temperature-tunable peptide and gold nanoparticle hybrid spheres. Biomacromolecules 12, 2518-2523 (2011)

38 Le, D. H. T., Hanamura, R., Pham, D.-H., Kato, M., Tirrell, D. A., Okubo, T. \& Sugawara-Narutaki, A. Self-assembly of elastin-mimetic double hydrophobic polypeptides. Biomacromolecules 14, 1028-1034 (2013).

39 Slocik, J. M., Stone, M. O. \& Naik, R. R. Synthesis of gold nanoparticles using multifunctional peptides. Small 1, 1048-1052 (2005).

40 Anh, T. T., Xing, M., Le, D. H., Sugawara-Narutaki, A. \& Fong, E. Elastin-based silverbinding proteins with antibacterial capabilities. Nanomedicine (Lond) 8, 567-575 (2013)

41 Addadi, L. \& Weiner, S. Control and design principles in biological mineralization. Angew. Chem. Int. Ed. 31, 153-169 (1992).

42 Addadi, L. \& Weiner, S. Crystals, asymmetry and life. Nature 411, 753-755 (2001).

43 Rong, J., Niu, Z., Lee, L. A. \& Wang, Q. Self-assembly of viral particles. Curr. Opin Colloid Interface Sci. 16, 441-450 (2011).

44 Guo, G., Truong, T. H.A., Tan, H., Ang, H., Zhang, W., Xu, C., Rui, X., Hu, Z., Fong, E. \& Yan, Q. Platinum and Palladium Nanotubes Based on Genetically Engineered Elastin-Mimetic Fusion Protein-Fiber Templates: Synthesis and Application in Lithium-02 Batteries, Chemistry. An Asian Journal (in press).

45 Gosline, J., Lillie, M., Carrington, E., Guerette, P., Ortlepp, C. \& Savage, K. Elastic proteins: biological roles and mechanical properties. Phil. Trans. R. Soc. Lond. B 357, 121-132 (2002)

46 Tsujimoto, Y. \& Suzuki, Y. Structural analysis of the fibroin gene at the 5' end and its surrounding regions. Cell 16, 425-436 (1979).

47 Mello, C. M., Senecal, K., Yeung, B., Vouros, P. \& Kaplan, D. (eds) Initia characterization of Nephila clavipes dragline protein. in Silk Polymers vol. 544 67-79 (American Chemical Society, Washington, DC, 1994). 
$48 \mathrm{Xu}, \mathrm{M}$. \& Lewis, R. V. Structure of a protein superfiber: spider dragline silk. Proc. Nat/. Acad. Sci. 87, 7120-7124 (1990)

49 Cappello, J., Crissman, J., Dorman, M., Mikolajczak, M., Textor, G., Marquet, M. \& Ferrari, F. Genetic engineering of structural protein polymers. Biotechnol. Prog. 6, 198-202 (1990).

50 Wen, H., Lan, X., Zhang, Y., Zhao, T., Wang, Y., Kajiura, Z. \& Nakagaki, M. Transgenic silkworms (Bombyx mori) produce recombinant spider dragline silk in cocoons. Mol. Biol. Rep. 37, 1815-1821 (2010)

51 Zhang, Y., Hu, J., Miao, Y., Zhao, A., Zhao, T., Wu, D., Liang, L., Miikura, A., Shiomi, K., Kajiura, Z. \& Nakagaki, M. Expression of EGFP-spider dragline silk fusion protein in BmN cells and larvae of silkworm showed the solubility is primary limit for dragline proteins yield. Mol. Biol. Rep. 35, 329-335 (2008).

52 Lazaris, A., Arcidiacono, S., Huang, Y., Zhou, J.-F., Duguay, F., Chretien, N., Welsh, E. A., Soares, J. W. \& Karatzas, C. N. Spider silk fibers spun from soluble recombinant silk produced in mammalian cells. Science 298, 472-476 (2002).

53 Fahnestock, S. R. \& Bedzyk, L. A. Production of synthetic spider dragline silk protein in Pichia pastoris. Appl. Microbiol. Biotechnol. 47, 33-39 (1997).

54 Krejchi, M. T., Atkins, E., Waddon, A. J., Fournier, M. J., Mason, T. L. \& Tirrell, D. A. Chemical sequence control of beta-sheet assembly in macromolecular crystals of periodic polypeptides. science $\mathbf{2 6 5}, \mathbf{1 4 2 7 - 1 4 3 2}$ (1994).

55 McGrath, K. P., Fournier, M. J., Mason, T. L. \& Tirrell, D. A. Genetically directed syntheses of new polymeric materials. Expression of artificial genes encoding proteins with repeating-(AlaGly)3ProGluGly- elements. J. Am. Chem. Soc. 114, 727-733 (1992).

56 Huemmerich, D., Helsen, C. W., Quedzuweit, S., Oschmann, J., Rudolph, R. \& Scheibel, T. Primary structure elements of spider dragline silks and their contribution to protein solubility. Biochemistry 43, 13604-13612 (2004).

57 Rammensee, S., Slotta, U., Scheibel, T. \& Bausch, A. R. Assembly mechanism of recombinant spider silk proteins. Proc. Natl Acad. Sci. 105, 6590-6595 (2008).

58 Scheibel, T. Spider silks: recombinant synthesis, assembly, spinning, and engineering of synthetic proteins. Microb. Cell Fact. 3, 14 (2004).

59 Min, B.-M., Jeong, L., Nam, Y. S., Kim, J.-M., Kim, J. Y. \& Park, W. H. Formation of silk fibroin matrices with different texture and its cellular response to normal human keratinocytes. International J. Biol. Macromol. 34, 223-230 (2004).

60 Huang, F., Sun, L. \& Zheng, J. In vitro and in vivo characterization of a silk fibroincoated polyester vascular prosthesis. Art. Organs 32, 932-941 (2008).

61 Fan, H., Liu, H., Wong, E. J. W., Toh, S. L. \& Goh, J. C. H. In vivo study of anterior cruciate ligament regeneration using mesenchymal stem cells and silk scaffold. Biomaterials 29, 3324-3337 (2008).

62 Meinel, L., Hofmann, S., Karageorgiou, V., Zichner, L., Langer, R., Kaplan, D. \& Vunjak-Novakovic, G. Engineering cartilage-like tissue using human mesenchymal stem cells and silk protein scaffolds. Biotechnol. Bioeng. 88, 379-391 (2004).

63 Meinel, L., Karageorgiou, V., Hofmann, S., Fajardo, R., Snyder, B., Li, C., Zichner, L., Langer, R., Vunjak-Novakovic, G. \& Kaplan, D. L. Engineering bone-like tissue in vitro using human bone marrow stem cells and silk scaffolds. J. Biomed. Mater. Res. A 71A, 25-34 (2004).

64 Humenik, M., Smith, A. M. \& Scheibel, T. Recombinant spider silk-biopolymers with potential for future applications. Polymers 3, 640-661 (2011)

65 Vepari, C. \& Kaplan, D. L. Silk as a biomaterial. Prog. Polym. Sci. 32, 991-1007 (2007).

66 Sugihara, A., Sugiura, K., Morita, H., Ninagawa, T., Tubouchi, K., Tobe, R., Izumiya, M., Horio, T., Abraham, N. G. \& Ikehara, S. Promotive effects of a silk film on epidermal recovery from full-thickness skin wounds. Proc. Soc. Exp. Biol. Med. 225 58-64 (2000)

67 Roh, D.-H., Kang, S.-Y., Kim, J.-Y., Kwon, Y.-B., Young Kweon, H., Lee, K.-G., Park, Y.-H., Baek, R.-M., Heo, C.-Y., Choe, J. \& Lee, J.-H. Wound healing effect of silk fibroin/alginate-blended sponge in full thickness skin defect of rat. J. Mater. Sci. Mater. Med. 17, 547-552 (2006).

68 Wang, Y., Blasioli, D. J., Kim, H.-J., Kim, H. S. \& Kaplan, D. L. Cartilage tissue engineering with silk scaffolds and human articular chondrocytes. Biomaterials 27, 4434-4442 (2006)

69 Wang, Y., Kim, U.-J., Blasioli, D. J., Kim, H.-J. \& Kaplan, D. L. In vitro cartilage tissue engineering with 3D porous aqueous-derived silk scaffolds and mesenchymal stem cells. Biomaterials 26, 7082-7094 (2005)

70 Marolt, D., Augst, A., Freed, L. E., Vepari, C., Fajardo, R., Patel, N., Gray, M., Farley, M., Kaplan, D. \& Vunjak-Novakovic, G. Bone and cartilage tissue constructs grown using human bone marrow stromal cells, silk scaffolds and rotating bioreactors. Biomaterials 27, 6138-6149 (2006)

71 Sofia, S., McCarthy, M. B., Gronowicz, G. \& Kaplan, D. L. Functionalized silk-based biomaterials for bone formation. J. Biomed. Mater. Res. 54, 139-148 (2001).

72 Wang, X., Kim, H. J., Xu, P., Matsumoto, A. \& Kaplan, D. L. Biomaterial coatings by stepwise deposition of silk fibroin. Langmuir 21, 11335-11341 (2005).

73 Altman, G. H., Horan, R. L., Lu, H. H., Moreau, J., Martin, I., Richmond, J. C. \& Kaplan, D. L. Silk matrix for tissue engineered anterior cruciate ligaments. Biomaterials 23, 4131-4141 (2002).

$74 \mathrm{Ma}, \mathrm{X}$., Cao, C. \& Zhu, H. The biocompatibility of silk fibroin films containing sulfonated silk fibroin. J. Biomed. Mater. Res. B 78B, 89-96 (2006).

75 Yang, Y., Chen, X., Ding, F., Zhang, P., Liu, J. \& Gu, X. Biocompatibility evaluation of silk fibroin with peripheral nerve tissues and cells in vitro. Biomaterials . 28, 1643-1652 (2007).
76 Weis-Fogh, T. A rubber-like protein in insect cuticle. J. Exp. Biol. 37, 889-907 (1960)

77 Su, R. S. C., Kim, Y. \& Liu, J. C. Resilin: Protein-based elastomeric biomaterials. Acta Biomaterialia 10, 1601-1611 (2013).

78 Kappiyoor, R., Balasubramanian, G., Dudek, D. M. \& Puri, I. K. Elastomechanical properties of resilin. Soft Matter 7, 11006-11009 (2011).

79 Renner, J. N., Kim, Y., Cherry, K. M. \& Liu, J. C. Modular cloning and protein expression of long, repetitive resilin-based proteins. Protein Expr. Purif. 82, 90-96 (2012).

80 Li, L. \& Kiick, K. L. Resilin-based materials for biomedical applications. ACS Macro Lett. 2, 635-640 (2013)

81 Li, L., Charati, M. B. \& Kiick, K. L. Elastomeric polypeptide-based biomaterials. Polym. Chem. 1, 1160-1170 (2010).

82 Qin, G., Rivkin, A., Lapidot, S., Hu, X., Preis, I., Arinus, S. B., Dgany, O., Shoseyov, O. \& Kaplan, D. L. Recombinant exon-encoded resilins for elastomeric biomaterials. Biomaterials 32, 9231-9243 (2011)

83 Li, L., Tong, Z., Jia, X. \& Kiick, K. L. Resilin-like polypeptide hydrogels engineered for versatile biological function. Soft Matter 9, 665-673 (2013).

84 Li, L., Teller, S., Clifton, R. J., Jia, X. \& Kiick, K. L. Tunable mechanical stability and deformation response of a resilin-based elastomer. Biomacromolecules 12 , 2302-2310 (2011).

85 McGann, C. L., Levenson, E. A. \& Kiick, K. L. Resilin-based hybrid hydrogels for cardiovascular tissue engineering. Macromol. Chem. Phys. 214, 203-213 (2013).

86 Bracalello, A. Santopietro, V. Vassalli, M. Marletta, G. Del Gaudio, R. Bochicchio, B. \& Pepe, A. Design and production of a chimeric resilin-, elastin-, and collagen-like engineered polypeptide. Biomacromolecules 12, 2957-2965 (2011).

87 Cao, Y. \& Li, H. B. Polyprotein of GB1 is an ideal artificial elastomeric protein. Nat. Mater. 6, 109-114 (2007).

88 Elvin, C. M., Carr, A. G., Huson, M. G., Maxwell, J. M., Pearson, R. D., Vuocolo, T., Liyou, N. E., Wong, D. C., Merritt, D. J. \& Dixon, N. E. Synthesis and properties of crosslinked recombinant pro-resilin. Nature 437, 999-1002 (2005).

89 Lv, S., Dudek, D. M., Cao, Y., Balamurali, M. M., Gosline, J. \& Li, H. B. Designed biomaterials to mimic the mechanical properties of muscles. Nature $465,69-73$ (2010)

90 Fang, J. \& Li, H. B. A facile way to tune mechanical properties of artificial elastomeric proteins-based hydrogels. Langmuir 28, 8260-8265 (2012).

91 Furst, B. (ed). Functional morphology of the heart. in The Heart and Circulation 95-109 (Springer, London, 2014).

92 Granzier, H. L. \& Labeit, S. The giant protein titin-a major player in myocardial mechanics, signaling, and disease. Circ. Res. 94, 284-295 (2004).

93 Linke, W. A., Rudy, D. E., Centner, T., Gautel, M., Witt, C., Labeit, S. \& Gregorio, C. C. I-band titin in cardiac muscle is a three-element molecular spring and is critical for maintaining thin filament structure. J. Cell Biol. 146, 631-644 (1999).

94 Hsin, J., Strumpfer, J., Lee, E. H. \& Schulten, K. Molecular origin of the hierarchical elasticity of titin: simulation, experiment, and theory. Ann. Rev. Biophys. 40, 187-203 (2011).

95 Radke, M. H., Peng, J., Wu, Y. M., McNabb, M., Nelson, O. L., Granzier, H. \& Gotthardt, M. Targeted deletion of titin N2B region leads to diastolic dysfunction and cardiac atrophy. Proc. Natl. Acad. Sci. USA 104, 3444-3449 (2007).

96 Anderson, B. R. \& Granzier, H. L. Titin-based tension in the cardiac sarcomere: molecular origin and physiological adaptations. Progr. Biophys. Mol. Biol. 110, 204-217 (2012).

97 Li, H. B., Linke, W. A., Oberhauser, A. F., Carrion-Vazquez, M., Kerkvliet, J. G., Lu, H., Marszalek, P. E. \& Fernandez, J. M. Reverse engineering of the giant muscle protein titin. Nature 418, 998-1002 (2002).

98 Javadi, Y., Fernandez, J. M. \& Perez-Jimenez, R. Protein folding under mechanical forces: a physiological view. Physiology 28, 9-17 (2013).

99 Tskhovrebova, L., Trinick, J., Sleep, J. \& Simmons, R. Elasticity and unfolding of single molecules of the giant muscle protein titin. Nature 387, 308-312 (1997).

100 Labeit, S. \& Kolmerer, B. Titins: giant proteins in charge of muscle ultrastructure and elasticity. Science 270, 293-296 (1995)

101 Granzier, H., Helmes, M. \& Trombitás, K. Nonuniform elasticity of titin in cardiac myocytes: a study using immunoelectron microscopy and cellular mechanics. Biophys. J. 70, 430-442 (1996).

102 Erickson, H. P. Reversible unfolding of fibronectin type III and immunoglobulin domains provides the structural basis for stretch and elasticity of titin and fibronectin. Proc. Natl Acad. Sci. USA 91, 10114-10118 (1994).

103 Carrion-Vazquez, M., Oberhauser, A. F., Fowler, S. B., Marszalek, P. E., Broedel, S. E., Clarke, J. \& Fernandez, J. M. Mechanical and chemical unfolding of a single protein: a comparison. Proc. Natl Acad. Sci. USA 96, 3694-3699 (1999).

104 Fukuda, N., Granzier, H. L., Ishiwata, S. \& Kurihara, S. Physiological functions of the giant elastic protein titin in mammalian striated muscle. J. Phys. Sci. 58, 151-159 (2008).

105 Duff, N., Duong, N. H. \& Lacks, D. J. Stretching the immunoglobulin 27 domain of the titin protein: the dynamic energy landscape. Biophys. J. 91, 3446-3455 (2006).

106 Caamano, S., Sarkar, A. \& Fernandez, J. M. The elasticity of individual titin PEVK exons measured by single molecule atomic force microscopy. Biophys. J. $8 \mathbf{8}$ 169a-169a (2005)

107 Duan, Y., DeKeyser, J. G., Damodaran, S. \& Greaser, M. L. Studies on titin PEVK peptides and their interaction (vol 454, pg 16, 2006). Arch. Biochem. Biophys. 456 , 232-232 (2006). 